\title{
Contributions
}

\section{Wladimir Zanoni* and Gabriel Weinberger Effects of Childcare Subsidies on Employment and Earnings of Low-Income Mothers}

\begin{abstract}
This study examines how childcare subsidies funded by the Child Care and Development Fund (CCDF - the most widespread childcare subsidy program in the United States) affect the employment status and earnings of low-income mothers. Employing a rich database of administrative records, we compute instrumental variables and control function estimates of the program's effects. As an exclusion restriction, we take advantage of differences in efficiency levels across administrative agencies that process subsidy applications and payments. CCDF-funded subsidies have short-term effects that are primarily driven by changes in the extensive margin of labor supply. Mothers who are either unemployed or earning closer to the upper cutoff of eligibility benefit the most from participation in this program.
\end{abstract}

Keywords: Eff ects of welfare programs, Labor Economics Policies JEL classification: I38, H53, J08

DOI 10.1515/bejeap-2014-0128

\section{Introduction}

The 1996 Personal Responsibility and Work Opportunity Act reformed welfare in the United States. One change was the establishment of the Child Care and Development Fund (CCDF) by extending money to all the states in the country to consolidate childcare subsidy programs for low-income working parents. The CCDF is aligned with welfare reform priorities. It is tasked with promoting selfsufficiency and encouraging employment of parents either currently using or at risk of dependence on public assistance. In year 2012, approximately 900 thousand families had their childcare subsidized by the CCDF program.

*Corresponding author: Wladimir Zanoni, Chapin Hall at the University of Chicago, $1313 \mathrm{E}$ 60th Street, Chicago, IL 60637, USA, E-mail: wzanoni@uchicago.edu

Gabriel Weinberger, Pardee RAND Graduate School, 1776 Main St, Santa Monica, CA 90401, USA, E-mail: Gabriel_Weinberger@rand.org 
Despite its broad coverage among low-income families, very little research has been conducted to evaluate how actual CCDF programs affect the employment outcomes of participant families in the United States. Research on the employment effects of CCDF subsidies is limited by the lack of longitudinal data that reliably identifies enrollment in this program while also monitoring employment outcomes. When data containing those characteristics is available, research on the employment effects of childcare subsidies is complicated by methodological challenges related to the facts that mothers do not select at random into this program (self-selection problems), and participation in the CCDF subsidies program is conditional upon employment (reverse causality problems).

The present research aims at extending our scientific knowledge of the employment effects of CCDF programs by estimating those effects using administrative data and using quasi-experimental methods that, we sustain, address both self-selection and reverse causality problems. From the methodological perspective, our paper exemplifies the use of alternative estimators, while theoretically and empirically compares the treatment effects generated by those. We develop a rich longitudinal database of linked administrative records from the state of Illinois and compute the ordinary least squares (OLS), instrumental variables (IVs) and control function (CF) estimates of those effects. In implementing the latter two estimators, we employ an exclusion restriction that exploits the fact that childcare subsidy payments are handled by multiple childcare resource and referral agencies (CCR\&R), and those agencies differ in the time they take to process such payments.

Payment processing times are a proxy for efficiency-driven transaction costs. We find those transaction costs to be inversely correlated with the probability that eligible parents apply for and/or receive childcare subsidy payments. Under conditions to be detailed later in this paper, we sustain that the treatment effects that emerge in our estimates can be identified because those processing times exert variations on employment outcomes solely through their effects on the probability of receiving a childcare subsidy.

This paper offers new ideas to estimate the employment effects of childcare subsidies on participant mothers using IVs and CF estimators. In particular, the paper proposes to use a new supply side variable (payment processing times) as an exclusion restriction to recover consistent estimates of the employment effects from participation in childcare subsidies. Besides the outcomes that we study in this paper, the methods here employed could also be used to evaluate other parental and/or child-related outcomes associated with this program.

This paper finds that childcare subsidies positively affect the employment probability and earnings of participant low-income mothers. We sustain that our parameters identify the treatment effects of childcare subsidies on employment outcomes. Those employment outcomes are primarily affected through the 
program's impact on the extensive margin of labor supply. The subsidy program's effects appear heavily concentrated in the first quarters after subsidy receipt, apparently while enrollment in the program lasts. We find that program effects vary with recipient neighborhood concentration of poverty, and with whether or not the mother participating in the program was employed before enrolling.

The paper is organized as follows: Section 2 briefly summarizes relevant literature and describes the subsidy program. Section 3 explains our approach to identify the treatment effects. Section 4 describes the data and presents descriptive statistics of key variables. Section 5 presents estimation results including subgroup analysis. Section 6 provides an overall assessment of our main results and offers conclusions.

\section{Background literature and the program description}

\subsection{Literature on the effects of childcare subsidies on employment outcomes}

Numerous empirical papers have analyzed the effects of early care and education programs on employment outcomes. ${ }^{1}$ Several government-sponsored childcare subsidy programs have been evaluated, either with actual data on program participation or through simulations. (A comprehensive review of this literature can be found in Blau (2003); Blau and Currie (2004)). However, very little research has investigated the effects of actual CCDF-sponsored childcare subsidies on employment outcomes.

In this section, we discuss recent papers evaluating the effects of government-subsidized early care and education programs on employment outcomes of low-income parents. Only one of those papers evaluates the effects of actual CCDF-sponsored childcare subsidies. We discuss, however, several other papers that employ rigorous empirical designs and/or share the same set of outcomes with the present research. The papers here reviewed are Gelbach (2002); Cascio (2009) and Fitzpatrick (2010); all of which evaluate the effects of pre-k or

1 Early influential research on this topic includes Heckman (1974); Blau and Robins (1998); Berger and Black (1992); Connelly (1992); Ribar (1995); Kimmel (1995); Michalopoulos, Robins, and Garfinkel (1992). Besides the work we review next, recent research includes Meyers, Heintze, and Wolf (2002); Witte, Queralt, and Griesinger (2000); Blau and Tekin (2007); Tekin (2007). 
kindergarten programs on employment outcomes. We also review the works of Tekin (2005) and Blau and Tekin (2007), which analyze survey data to estimate the impacts of childcare subsidy receipt on the employment status of single mothers. Separately, we describe the related works of Meyers, Heintze, and Wolf (2002), who analyze the employment effects of subsidy receipt on labor market activity of low-income mothers in California; and Meyers, Heintze, and Wolf (2002) who evaluate the CCDF program's effects on employment outcomes through a randomized control trial in Cook County, Illinois (the same program whose effects we evaluate in this research).

The work of Gelbach (2002) is a widely cited study that analyzes the effects of kindergarten enrollment (an implicit childcare subsidy) on the wages and employment of single mothers whose youngest child is 5 years old. Quarter of birth is employed as an exclusion restriction that affects enrollment in kindergarten discontinuously. Using an IV estimator, the study finds that the wage and/or salary income and the work probability of mothers increased (by $24 \%$ and $6 \%$ correspondingly) when their youngest child aged 5 years old attends kindergarten.

The work by Cascio (2009) exploits the dynamics of the expansion in the supply of kindergarten seats in public schools in the 1960s and 1970s. Using census data in a difference-in-differences framework, the author exploits variation in timing and geography (states) that characterized the expansion of kindergarten funding during those two decades. Cascio finds that the employment status of single mothers with children eligible to enter kindergarten (and no younger children) increased substantially as the result of the expansion in this implicit childcare subsidy program (4.5 percentage points increase in employment).

The study by Fitzpatrick (2010) employs a regression discontinuity design to identify the effects of preschool programs on parental employment outcomes. This research isolates the effects on earnings and employment of mothers who enrolled their youngest children in universal preschool programs in Georgia and Oklahoma. Using 2000 census data, this work compared the earnings of mothers whose youngest children were aged in the region of 4 years old, as this age defined the eligibility cutoff for the preschool programs in both states. The study finds that mothers who enrolled their youngest child in universal pre-k programs did not increase their earnings, and their employment probabilities did not change.

Tekin (2005) studies the effects of childcare subsidy receipt reported by single mothers in the 1999 National Survey of America's Families. The paper investigates the joint decision of work and childcare type using policy-relevant measures at the state level as IVs to induce exogenous variability in those decisions. The paper finds that childcare subsidy receipt increases by $15.3 \%$ the probability that mothers jointly decide to work and utilize childcare of various types. Using the same database as Tekin (2005), Blau and Tekin (2007) 
compute two-stage least squares estimates using county dummies as identifying instruments. They find that childcare subsidy receipt increases employment probability by 33 percentage points.

In Meyers, Heintze, and Wolf (2002), the probability of work conditional upon subsidy receipt is analyzed in a sample of low-income California mothers who received welfare benefits in 1992 (pre-welfare reform). Their structural equation modeling strategy used a variable measuring the mothers' knowledge of the childcare system as an exclusion restriction. They found that subsidy receipt had a significant and substantial impact on the mother' s probability of work.

In the work by Michalopoulos, Lundquist, and Castells (2010), mothers in Cook County, Illinois, were randomly assigned to either a treatment group receiving childcare subsidies or to a control group. All participant mothers had incomes just above the eligibility threshold for childcare subsidies receipt between $50 \%$ and $65 \%$ of Illinois's median income. The authors found no evidence of significant effects of childcare subsidies on either the earnings or employment outcomes of participant mothers.

The works of Gelbach (2002); Cascio (2009) and Fitzpatrick (2010) are all highly relevant for understanding the effects of pre-k and kindergarten on the labor supply of mothers. However, because of differences in the populations they serve, the employment effects of pre-k and kindergarten are likely to differ from the employment effects of CCDF subsidies. Note that different from CCDF subsidies, pre-k and kindergarten programs do not condition participation on either household income or employment status. Pre-k and kindergarten programs also set strict age eligibility thresholds, which CCDF subsidies do not. Differences in eligibility rules across programs will make participants different in terms of the observable characteristics that are affected by those rules (i.e. household income, employment status and child age). Moreover, and perhaps more importantly for evaluation purposes, mothers across those programs will also likely differ in terms of unobservable characteristics that are relevant to explain their program choices and their employment outcomes (as, for instance, employed low-income mothers might exhibit higher levels of ability than unemployed ones). Despite its overall relevance, evaluation of the employment effects of CCDF programs is not sufficiently well informed by the knowledge of how pre-k and kindergarten programs affect those outcomes.

The works of Tekin (2005), Blau and Tekin (2007) and Meyers, Heintze, and Wolf (2002) develop empirical analysis that properly describes the nature of the endogenous treatment effect problem and propose methods to rigorously address it. In particular, their works exemplify the use of exclusion restrictions to address the statistical challenges to consistent estimation of the effects of childcare subsidies on the employment status of low-income mothers. Those papers underscore 
the complexity of using nonexperimental methods for this type of research. Obtaining unbiased estimates requires employing valid exclusion restrictions. Even with sounded exclusion restrictions, as those utilized in the reviewed papers, concerns about endogenous treatment effects appear still unresolved.

While the study conducted by Michalopoulos and colleagues mitigates selection bias concerns (because it is a randomized experiment), their research design also imposed limits on their finding's external validity. They found that all mothers eligible for the randomization derived their incomes mainly from wages and had stable jobs before their participation in the study. As the authors acknowledge, this research design aspect left very little room to find any effects of childcare subsidies upon employment outcomes. By definition, the external validity of that study's findings speaks of employed mothers with higher incomes than the average mothers who are eligible for CCDF subsidies. We hypothesize that the average elasticity of childcare costs to employment outcomes among mothers in that study is potentially lower than the average elasticity of the average mother who is eligible for CCDF childcare subsidies. The present research tries to understand the effects of childcare subsidies on employment outcomes of very low-income mothers. Those mothers are unlikely to be represented in the study carried out by Michalopoulos and colleagues.

\subsection{Childcare subsidies in Illinois}

As stated in the introduction, the CCDF program is a US federal program that is administered and also partially funded by the states. Since 1997, the state of Illinois has combined state and CCDF funds to support employment of lowincome working parents through the Child Care Assistance Program (CCAP). ${ }^{2}$ In 2012, mothers of nearly 130,000 children in Illinois received childcare subsidies amounting to $\$ 600$ million. According to the Illinois Department of Human Services, CCAP assists parents so that they can "continue working and contribute to the healthy emotional and social development of their children." The program specially targets low-income single mothers who are either dependent, or at risk of becoming dependent, on public assistance.

2 A current description of the history of the CCDF program can be found online in the 2014 Background Material and Data on the Programs within the Jurisdiction of the Committee on Ways and Means: http://greenbook.waysandmeans.house.gov/2014-green-book (accessed December 2, 2014). Blau (2003) and Blau and Currie (2004) also provide excellent detailed analysis of the CCDF program. Our characterization of the program is based on those sources. Description of the Illinois CCAP presented here summarizes our review of the yearly "Plan for CCDBG Services in Illinois” from 1998 to 2011. 
As in all other states, the Illinois childcare subsidy program issues certificates or vouchers to parents upon request, primarily through CCR\&R. Parents are entitled to childcare for children from birth to age 13 if they meet the program's eligibility criteria. (The criteria include an income threshold level that varies depending on household size.) Parents must be employed when applying for the program, but some parents attending school and/or participating in job training activities are also eligible (priority is given to participants in the Transfer Aid for Needy Families [TANF] program). Employed parents form, by far, the largest group of subsidy recipients (for instance, in FY 2000, around 90\% of CCAP participants fell under the employment eligibility category).

Eligibility for childcare subsidy benefits is reevaluated every 6 months (workers paid in cash and the self-employed are reassessed every 3 months), and parents are required to notify the relevant CCR\&R of any change in work, household composition and/or income status between redetermination periods. Eligible households are required to share in childcare costs by making copayments, the amounts of which vary with household income, size, number of children in care, hours in care and type of provider chosen. CCAP subsidizes full-time and part-time childcare in licensed or license-exempt childcare centers and homes, in-home nonrelative care and care provided by relatives. Administrative records for year 2000 (the baseline year in our data) reveal that around 10,000 children ages 0-5 entered CCAP for the first time. After 2000, those children had frequent exits and reentries into CCAP, with nearly 20\% having two or more periods of receiving the childcare subsidy. For about 50\% of CCAP participants, the length of the first period spent in the program parallels the redetermination cycle (either 6 or 3 months), as participants only remain in the program as long as the first of those cycles last.

\section{Empirical strategy}

Prototypical problems of nonrandom selection and reverse causality are major challenges to generating unbiased estimates of the treatment effects involved in this program's evaluation. Nonrandom selection problems arise because some mothers with idiosyncratic characteristics perceive higher expected utility from applying and utilizing childcare subsidies than others. Reverse causality results from program eligibility rules that make participation contingent on mothers' enrollment in employment-related activities. If selection and reverse causality problems are not addressed, estimates of the effects of childcare subsidies on employment outcomes will be biased. 


\subsection{Estimators and the parameters that they identify}

Our empirical analysis employs OLS, IVs and CF (or selection correction models) estimators to estimate the effects of childcare subsidies on the employment outcomes of participant mothers. Next we discuss potential differences between the estimates generated by those estimators following insights fully developed in Heckman and Navarro-Lozano (2004), Heckman, Urzua, and Vytlacil (2006) and Heckman (2007).

As stated, in this study, we use OLS regression - a parametric matching estimator - to estimate the effects of interest. The key identifying assumption of OLS is one of "matching on observables": conditional on attributes observed by the researcher, the distribution of the expected employment outcomes is independent of the childcare subsidy receipt status. This conditional independence assumption cannot be empirically tested, but it can be heuristically sustained whenever, as in our case, the set of conditioning variables is broad and theoretically consistent. Notice that, given the employment eligibility requirement, even if the matching on observables assumption is valid, reverse causality problems might still remain in OLS regression. Under the assumptions of matching on observables, a linear link function and no reverse causality, OLS will identify the effect of childcare subsidies on those mothers who participate in the program (will estimate a treatment on the treated effects parameter - TT).

It is possible that, even after we match participants to nonparticipants on the rich set of covariates we have, some remaining unobserved factors still drive mothers to participate in the childcare subsidies program. The IV estimator attempts to mimic experimental random assignment by inducing variation in the employment outcomes through changes in the treatment status that are motivated by an IV. The two key identifying assumptions of the IV estimator are that there is positive correlation between the instrumental and treatment variables, and there is no correlation between the unobserved components that explain the employment outcomes and the instrument. IV also assumes that the individual responses to the instrument's variability are homogenous across people affected by the instrument. Under those assumptions, IV identifies the effects of the childcare subsidy program on those induced to participate as the result of changes in the instrument (a local average treatment effect parameter, which will be equal to TT if the response to the instrument is the same for everyone conditional on covariates). Notice that, different from OLS, because selection into childcare subsidies is driven by an exogenous source, the direction of causality in this estimator is clearly from childcare subsidy receipt to employment outcomes. 
In general, however, it is not possible to rule out that people have heterogenous unobserved gains (instead of homogenous ones) that drive their selection into programs, even after controlling for observable characteristics (i.e. we cannot a prior rule out that there is "essential heterogeneity"). In the presence of essential heterogeneity IV fails to generate interpretable parameter estimates of treatment effects. As an alternative, CF estimators explicitly deal with heterogeneity in unobserved idiosyncratic gains by modeling that heterogeneity (often semi-parametrically - as we do in this paper) as a function of observables and an IV. The use of an IV in the CF approach allows to induce variability in the heterogenous unobserved gains that is independent of the observed gains that drive participation. This modeling strategy identifies treatment effects in areas of common support near the boundaries of the probability of participation (i.e. in areas of common support where the probabilities of participation are near 0 and/or 1-called "identification at infinity").

In comparing estimates from these three estimators we assume that the parameter estimates from OLS are more likely to be biased, primarily because of unaddressed reverse causality problems. Big differences in the parameter estimates from IV and CF estimators are difficult to characterize because they would suggest that essential heterogeneity is present limiting our ability to interpret the IV parameter estimates. However, small differences in the parameter estimates from those two last estimators would suggest that essential heterogeneity is not a problem, and that both IV and CF identify the same underlying parameter (i.e. both express the effects of the childcare subsidy program on the employment outcomes of participant mothers (the TT parameter)).

\subsection{The instrumental variable}

In applying IV and CF estimators we make use of a supply-side exclusion restriction: the median time taken by administrative CCR\&R agencies in processing childcare subsidy payments. As shown in Section 5.1, the probability of childcare subsidy receipt is inversely related to those CCR\&R processing times. We sustain that, under certain conditions, CCR\&R processing times affect employment outcomes of childcare subsidy participant mothers only through their impact on the probability of subsidy receipt.

Among other activities, CCR\&R agencies are tasked with handling childcare subsidy applications, processing monthly payments and monitoring the eligibility status of households receiving program benefits. Assignment of cases to specific CCR\&Rs reflects the household's region of residence: 17 CCR\&Rs attend to 250 Illinois' counties (see Appendix B for counties CCR\&R assignments in year 2000). 
CCR\&Rs play a central role as intermediaries among the state, household and childcare providers. CCR\&R agencies differ in the type of childcare subsidy cases they handle because regional populations vary in composition.

At a very general level, CCR\&Rs attend populations that are different in size, degree of urbanicity, income and average educational levels. Consequently, an unconditional comparison of processing times across CCR\&Rs will reflect systematic differences in the type of cases handled by those agencies (i.e. regionally driven population differences). In order to ensure that the processing time variable only reflects differences in efficiency levels (or transaction costs), systematic differences in the characteristics of the underlying populations served by each CCR\&R need to be held constant. We sustain that differences in processing times across CCR\&Rs serve as a valid exclusion restriction if we hold constant the characteristics of those households differentially assigned to the CCR\&Rs by the region of residence rule.

This logic can be formalized in an omitted variable bias framework. Consider the following structural model (herein referred to as the true datageneration process, or DGP), which represents participation in the childcare subsidies program and employment outcome equations:

$$
\begin{aligned}
& E_{i k}=D_{i k} \delta+X_{i k} \varphi+Z_{i k} \pi+\varepsilon_{i k}, \\
& D_{i k}=P_{i k} \alpha+X_{i k} \tau+Z_{i k} \psi+\omega_{i k},
\end{aligned}
$$

where $E_{i k}$ represents the employment outcome for mother $i$ whose childcare subsidy application is handled by CCR\&R agency $k ; D_{i k}$ is an indicator variable for participation of mother $i$ in the childcare subsidy program; $X_{i k}$ is a vector of relevant observable characteristics of the mothers, the households they form and the neighborhood in which they live, all of which affect the probability of selection into CCDF childcare subsidy program and employment outcomes. We also denote $Z_{i k}$ as a set of variables that predict the CCR\&R region-level propensity of an average household, served by CCR\&R agency $k$, to apply for and receive childcare subsidies. The variable $P_{i k}$ is the exclusion restriction of CCR\&R processing time. Following Black and Smith (2006), we denote $\tilde{D}_{i k}$ the "Yulized residuals" decomposition from regressing $D_{i k}$ on $X_{i k}$ and $Z_{i k}$, and $\tilde{P}_{i k}$ denotes the Yulized residuals decomposition from regressing $P_{i k}$ on $X_{i k}$ and $Z_{i k}$. It can be shown that the probability limit of the two-stage $\operatorname{IV}\left(P_{\lim }\left(\delta^{\mathrm{IV}}\right)\right)$ estimator for $\delta$ (the treatment effect of interest) is

$$
P_{\lim }\left(\delta^{\mathrm{IV}}\right)=\delta+\frac{\operatorname{Cov}\left(\tilde{P}_{i k}, \varepsilon_{i k}\right)}{\operatorname{Cov}\left(\tilde{P}_{i k}, \tilde{D}_{i k}\right)} .
$$

If instead of using the true DGP we omitted $Z_{i k}$ so that structural equation parameters are estimated based on 


$$
\begin{gathered}
E_{i k}=D_{i k} \delta+X_{i k} \varphi+\varepsilon_{i k}, \\
D_{i k}=P_{i k} \alpha+X_{i k} \tau+v_{i k},
\end{gathered}
$$

then the bias estimating the treatment effect in this system $(\operatorname{Bias}(\delta))$ is equal to a nonzero expression

$$
\operatorname{Bias}(\delta)=P_{\lim }\left(\delta^{\mathrm{IV}}\right)-\delta=\frac{\operatorname{Cov}\left(\tilde{P}_{i k}, Z_{i k}+\varepsilon_{i k}\right)}{\operatorname{Cov}\left(\tilde{P}_{i k}, \tilde{D}_{i k}\right)} .
$$

Our identification strategy relies on the use of estimators that by holding constant factors in $Z_{i k}$ exploits exogenous assignment to childcare subsidies $D_{i k}$ on the basis of the processing time of payments (the exclusion restriction $P_{i k}$ ) and on the use of a rich set of covariates in the conditioning set $X_{i k}$. Holding constant factors in $Z_{i k}$ is a necessary condition that allows identification of the treatment effect of interest.

\section{Data}

\subsection{Database description}

For this research we built a longitudinal database of linked administrative records that tracks the histories of quarterly earnings and childcare subsidy participation by Illinois' low-income mothers. The units of analysis in our data are mothers with at least one child aged 5 years or younger who were active grantees of the Food Stamps program during year 2000 in Illinois. Only mothers between 18 and 35 years old during that year were chosen. The mothers were coded as childcare subsidy recipients if they had started a new childcare program cycle during 2000, and had not participated in this program in the preceding 2 years. Classified that way, our population includes 9,599 mothers who received childcare subsidies and 38,819 mothers who did not.

We assigned a baseline time of reference for all mothers in our population. The baseline time of reference for mothers receiving CCDF childcare subsidies is the quarter in year 2000 during which they started participating in the program. The baseline time of reference for nonparticipant mothers is the quarter when they were first identified as active recipients of Food Stamps in year $2000 .^{3}$

3 We tested sensitivity of results to various rules by assigning baseline periods to define a preand post-baseline period to nonrecipient mothers. Those rules included randomly assigning nonrecipient mothers an age for their youngest child, and also stratifying them so that the proportions of subsidy recipients each quarter equaled the proportion of nonrecipient mothers. Our results are invariant to those choices. 
Anchored on the baseline time of reference, earnings, employment status and participation in TANF were monitored prospectively and retrospectively. In the rest of this study, we will use the labels "baseline period" and "baseline time of reference" alternatively. We will also use the terms pre- and/or post-baseline periods to refer to the time preceding and/or subsequent to the baseline period.

As described in Section 3, we will employ the variable "CCR\&R agency processing time of childcare subsidy payments" $P_{i k}$. In our data, each mother is assigned a "processing time" equivalent to the median number of days that would have passed between when a childcare service was provided and when it was paid for. Those processing times are conditional on household addresses and vary uniquely across CCR\&R agencies and time (across 17 agencies and 4 baseline quarters in 2000). Those processing times $P_{i k}$ were calculated with reference to participating households residing in the same CCR\&R's region of service, and during the same pre-baseline period that is associated with the families in our study.

Earnings data was tracked from Unemployment Insurance (UI) program records, childcare subsidies participation was identified in the Illinois Child Care Tracking System (CCTS). Longitudinal enrollment data in TANF and Food Stamps programs were recovered from records in the Illinois Longitudinal Public Assistance Database (ILPARD). Appendix A describes those databases in full detail. Using those earnings records we computed two outcome variables that we analyze in this paper. The first outcome variable that we analyzed in this paper is the employment status of mothers which was constructed as a binary indicator variable taking value 1 if the mother is employed and 0 otherwise. The second variable recovers earnings and/or the log of those earnings.

In addition to data describing longitudinal employment status, earnings and participation in TANF and Food Stamp programs, our database also includes a rich set of demographic variables that characterize the mothers and their households in year 2000. Anchored on the geographical coordinates of the household's addresses (also called geocodes), the database also includes neighborhood characteristics at the block group level, imputed from the 2000 census. In the following sections we describe what these variables say about the use of childcare subsidies as well as about differences in employment outcomes across childcare subsidy receipt status.

\subsection{Longitudinal series of earnings, employment and participation in TANF}

Figure 1 presents the longitudinal evolution of the earnings, employment status and participation in the TANF for both childcare subsidy recipients (dotted line) 

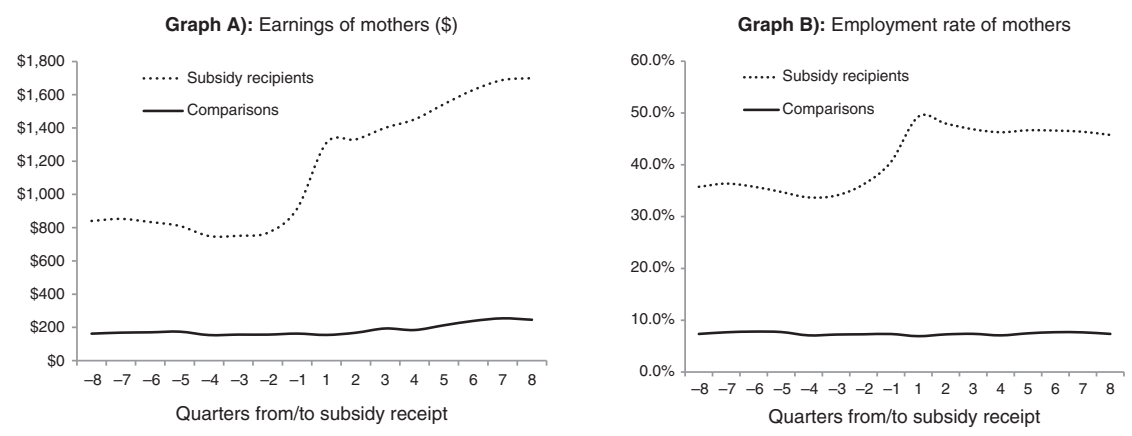

Graph C): Welfare participation (\% in TANF)

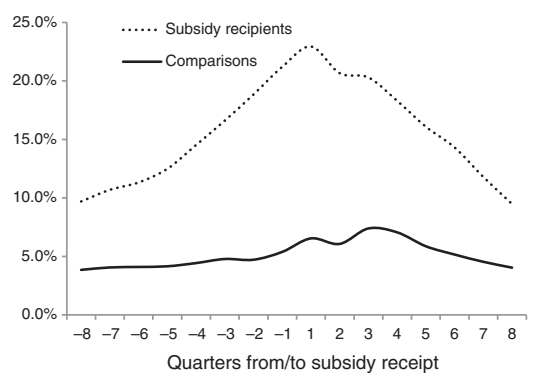

Figure 1: Earnings, employment status and TANF participation rates (by treatment status) Notes: The vertical axes represent average quarterly real earnings (graph A), employment rate (graph B) and TANF participation rate (graph C). The horizontal axis indicates the number of quarters before/after the quarter of subsidy receipt (normalized with 0 as the baseline period).

and nonrecipients (solid line). In the figure, mean values are plotted in a normalized time frame, ranging from eight-quarters prior to eight-quarters after subsidy receipt. (Zero is the baseline period, and negative and positive values are the pre- and post-baseline periods, respectively.)

One remarkable feature of Figure 1 is the sharp discontinuities that emerged for the earnings, employment rates and welfare participation for the group of subsidy recipients after they participated in the program. Earnings and employment rates increased from around $\$ 660$ and 39\% the quarter before subsidy receipt, to $\$ 1,150$ and $52 \%$ in the quarter after subsidy receipt. TANF participation rates also changed notably after subsidy receipt, decreasing from $41 \%$ onequarter before to $27 \%$ three-quarters after subsidy receipt. An unconditional comparison of the earnings, employment rates and welfare participation series in Figure 1 suggests that childcare subsidies could have had an impact upon those outcomes. 
In graphs $\mathrm{A}$ and $\mathrm{B}$ of Figure 1, it can be seen that earnings and employment rates follow similar paths for all mothers up to three-quarters before the baseline period. However, those trends in the pre-baseline period become steeper among subsidy recipients around three-quarters before subsidy receipt. The changes in the pre-baseline period trends in both earnings and employment are not observed among mothers who will not use the subsidy program. Mothers who experience increases in their employment rates in the pre-baseline period are more likely to participate in childcare subsidies than mothers who do not.

Graph $\mathrm{C}$ shows differences by subsidy receipt status in the time series that characterizes the rate of participation in the TANF program. During the pre-baseline period, the TANF program participation rate among mothers who receive childcare subsidies increases at a higher rate than among mothers who did not receive it. That pattern is consistent with the fact that TANF recipients are given priority to receive childcare subsidies under the program's eligibility rules. Along with the pre-baseline dynamics of employment and earnings, participation in TANF also appears to be another driver of mothers' choice of childcare subsidies.

\subsection{Baseline differences in selected characteristics}

Table 1 presents some descriptive statistics of key variables characterizing the mothers in our study at the baseline period. The variables shown are thought to be associated with the probability of selection into childcare subsidy programs and also with differences in employment outcomes across childcare subsidy receipt status. The upper panel of Table 1 shows attributes of the mothers, their children and their households (which we labeled "Households"), and the bottom panel describes characteristics of their residential neighborhoods.

Albeit the differences in all of the variables presented in Table 1 are statistically significant (as expected given a population of more than 48,000 mothers), the mothers in our data are analytically similar across their subsidy receipt status in numerous dimensions. For instance, mothers exhibit very similar mean ages (around 25 years old with a 1-year average difference), have equivalent numbers of children, form households with equivalent number of members and their likelihood of being black is very similar. In terms of the characteristics that describe their neighborhoods, mothers who received childcare subsidies are also remarkably similar to nonrecipients in many dimensions, such as the average years of schooling and median household income.

Table 1 also shows that mothers receiving subsidies are less likely to be white and more likely to be Hispanic than mothers who do not use childcare subsidies. Childcare subsidy recipients also live in neighborhoods with a higher 
Table 1: Descriptive statistics of selected variables (by treatment status)

\begin{tabular}{|c|c|c|c|c|}
\hline & \multicolumn{2}{|c|}{ Comparison group } & \multicolumn{2}{|c|}{ Subsidy recipients } \\
\hline & Mean & Std. dev. & Mean & Std. dev. \\
\hline \multicolumn{5}{|l|}{ Households $^{1}$} \\
\hline Number of children aged $0-5$ & 1.45 & 0.66 & 1.37 & 0.6 \\
\hline Number of children & 2.26 & 1.17 & 2.09 & 1.11 \\
\hline Number of adults females & 1.11 & 0.35 & 1.08 & 0.36 \\
\hline Number of adults males & 0.17 & 0.53 & 0.36 & 0.41 \\
\hline Proportion of mothers foreign born & 0.02 & 0.21 & 0.05 & 0.13 \\
\hline Age of mother & 25.21 & 4.47 & 26.13 & 4.2 \\
\hline Age of youngest $\mathrm{HH}$ member & 1.96 & 1.31 & 2.14 & 1.2 \\
\hline AGE of oldest $\mathrm{HH}$ member & 26.45 & 6.47 & 27.78 & 6.23 \\
\hline Number of $\mathrm{HH}$ members & 3.54 & 1.42 & 3.53 & 1.46 \\
\hline Proportion whites (non-Hisp.) & 0.34 & 0.4 & 0.2 & 0.47 \\
\hline Proportion blacks (non-Hisp.) & 0.38 & 0.4 & 0.38 & 0.42 \\
\hline Proportion Hispanics & 0.05 & 0.22 & 0.2 & 0.22 \\
\hline Time in Food Stamps when sampled (QTRS) & 3.88 & 3.78 & 2.9 & 4.15 \\
\hline \multicolumn{5}{|l|}{ Neighborhood ${ }^{2}$} \\
\hline Female employment rate (with child $<6$ ) & 0.87 & 0.09 & 0.89 & 0.14 \\
\hline Proportion of HHS at or below $100 \% \mathrm{FPL}$ & 0.24 & 0.15 & 0.19 & 0.18 \\
\hline Proportion HHS B/W $100 \%$ and $199 \% \mathrm{FPL}$ & 0.22 & 0.1 & 0.22 & 0.1 \\
\hline Proportion HHS $200 \%$ or more & 0.54 & 0.19 & 0.58 & 0.21 \\
\hline Median $\mathrm{HH}$ income & 32,487 & 13,755 & 34,995 & 14,593 \\
\hline Median $\mathrm{HH}$ income (race white) & 29,085 & 19,870 & 33,792 & 27,277 \\
\hline Median HH income (race black) & 25,317 & 24,682 & 22,699 & 20,754 \\
\hline Years in rent & 6.33 & 2.81 & 5.68 & 3.47 \\
\hline Median value of homes (owners) & 92,782 & 61,961 & 99,889 & 60,623 \\
\hline Rent to income proportion & 31.64 & 6.65 & 29.94 & 7.17 \\
\hline Average years of schooling & 12.12 & 1.49 & 11.82 & 1.19 \\
\hline Proportion with bachelor degree & 0.09 & 0.08 & 0.09 & 0.09 \\
\hline
\end{tabular}

Notes: The table presents mean values of the distribution of the specified variables and their corresponding standard deviations by treatment status; ${ }^{1}$ The data source for household characteristics is the ILPARD database (see Appendix A for details on this database); ${ }^{2}$ Neighborhood characteristics are calculated from geographic data reported by the 2000 US census at the block-group level.

median value of their homes (conditional on ownership) compared to nonrecipients. Households receiving childcare subsidies are also more likely to have an adult male present than households not receiving support from the program.

In summary, Table 1 indicates that mothers receiving childcare subsidies differ from mothers who do not receive subsidies across some dimensions, many of which could confound the unconditional probabilities of using a childcare 
subsidy and the comparison of employment outcomes by treatment status (notably across race and presence of males in the households). Mothers look very similar across many characteristics (especially in the characteristics of the neighborhoods where they reside). The variables in Table 1, along with the prebaseline series of earnings, employment and participation in TANF illustrated in Figure 1, form a rich set of observable characteristics to be used in our conditioning set. Those variables will help to control for heterogeneity in observables in the context of our identification strategy, as delineated in Section 3.

\subsection{Examining the instrumental variable}

Appendix $\mathrm{C}$ shows basic descriptive statistics of the IV for the population analyzed and explores some features of the nature of the correlation between the instrumental variable and the treatment variable. From Table 1 Appendix $C$ we can infer that the average median duration of processing time is approximately 40.5 days, and the distribution of this variable ranges from 37 to 52.5 days. It is important to highlight that the variability in processing time is levered from 68 data points corresponding to 17 CCR\&Rs and 4 time points (1 per each quarter of 2000). Comparing unconditional processing times by treatment status, we can see that households in the treatment group experience longer processing times than households in the comparison group (the order of magnitude of this difference is of approximately 0.20 standard deviations). However, in Table 2 Appendix $C$ we show that conditioning on the CCR\&R region factors (variables in vector $Z$ from eq. [1]) and county fixed effects, both the correlation coefficient and the coefficient estimate of a linear regression of the treatment variable on the processing time variable flips signs from positive to negative. Once CCR\&R caseload characteristics and county fixed effects are held constant, the probability of subsidy receipt decreases in processing time.

Anticipating net benefits from participation in the program, some households could act strategically by moving to CCR\&R regions with faster processing times before applying for the subsidy program. This type of behavior would invalidate the CCR\&R processing time as an IV, since that variable could not be claimed to be exogenous to households, but the result of heterogeneity in expected gains from CCDF participation that affects household's behavior. Table 3 in Appendix $C$ shows the probability that an average household in our sample would change its CCR\&R region of residence, either one- or two-quarters before the baseline period. The data reveals that moving strategically across CCR\&R regions in the pre-baseline period is a fairly rare phenomenon (with very low probabilities of occurrence that, at most, reach $1.125 \%$ ). This result increases our confidence in the validity of the exclusion restriction as, apparently, the 
costs of strategically moving across CCR\&R regions to gain faster access to the CCDF program appears greater than the expected benefit associated with participating in the program for the vast majority of households.

\section{Results}

\subsection{Participation equation}

As explained in Section 3, our identifying hypothesis is that conditional on observables (vectors $X$ and $Z$ from eq. [1]; subscripts omitted to ease reading), the probability of receiving a childcare subsidy should "exogenously" decrease as payment processing time increases. Table 2 evaluates the statistical significance, power and sign of the exclusion restriction $P$ (processing time) across alternative model specifications of the probability of childcare subsidy receipt. The five columns presented in the table alternatively condition on a set of covariates that match childcare subsidy recipients to nonrecipients across a number of observable characteristics $X$, and a vector of CCR\&R agency characteristics that describe the agency-specific population of subsidy recipients $Z$. Covariates in vector $X$ include $\mathrm{HH}$ size, number of children aged 0-5, number of adult males, age of the mother, age of youngest child and indicator variables if the mothers are of race black, white or Hispanic and if they are foreign born. Vector $X$ also adds 2000 Census block-group measures of median income, population size, ratio income to poverty, average years in rent, average years of schooling and proportion of people with a bachelor degree. Additionally, vector $X$ includes pre-baseline earnings, along with dummies for employment status and for participation in welfare variables as described in Section 4.2 (from eight- to one-quarters before subsidy receipt). Variables in vector $Z$ include median time providers have received childcare subsidy vouchers, the proportion of black, white and Hispanic cases, the proportion of childcare cases related to children aged $0-3,3-5$ and 5 and older, the proportion of cases relating to licensed and unlicensed childcare facilities and total number of cases handled by the CCR\&R of reference. Vector $Z$ also includes county fixed effects.

The five specifications of the first-stage equation presented in Table 2 differ in the set of covariates that they include. In that table, we study how the sign and power of the IV, the model's goodness of fit and the potential endogeneity of the treatment indicator variable change across model specifications.

In model 1 of Table 2, the value of the $F$-statistic suggests that, unconditionally, the processing time variable strongly predicts the probability of 
Table 2: OLS coefficients of the exclusion restriction in the first stage equation

\begin{tabular}{|c|c|c|c|c|c|}
\hline & \multirow[b]{2}{*}{ Model 1} & \multirow[b]{2}{*}{ Model 2} & \multirow[b]{2}{*}{ Model 3} & \multicolumn{2}{|c|}{ Specifications of models } \\
\hline & & & & Model 4 & Model 5 \\
\hline Processing time & 0.022 & 0.005 & 0.039 & 0.0372 & -0.114 \\
\hline Standard error & $(0.002)$ & $(0.002)$ & $(0.009)$ & $(0.008)$ & $(0.006)$ \\
\hline Covariates $(X \text { vector })^{1}$ & No & Yes & No & Yes & Yes \\
\hline $\begin{array}{l}\text { CCR\&R }(Z \text { vector/no } \\
\text { county FE })^{2}\end{array}$ & No & No & Yes & Yes & Yes \\
\hline County fixed effects ${ }^{3}$ & No & No & No & No & Yes \\
\hline$N$ & 48,418 & 48,098 & 48,418 & 48,098 & 47,933 \\
\hline Root mean squared error & 0.397 & 0.361 & 0.319 & 0.299 & 0.233 \\
\hline $\begin{array}{l}\chi^{2}(q) \text { statistic (Hausman } \\
\text { test) }\end{array}$ & $\begin{array}{r}60.3 \\
(P=0.00)\end{array}$ & $\begin{array}{r}2.1 \\
(P=0.15)\end{array}$ & $\begin{array}{r}-11.2 \\
(P=1.00)\end{array}$ & $\begin{array}{r}-0.3 \\
(P=1.00)\end{array}$ & $\begin{array}{r}-5.2 \\
(P=1.00)\end{array}$ \\
\hline F-statistic of the $\mathrm{IV}^{5}$ & 421.4 & 17.8 & 19.7 & 17.9 & 416.2 \\
\hline
\end{tabular}

Notes: The table presents OLS coefficient estimates (standard errors below) of the processing time variable on the probability of childcare subsidy receipt. The rows below the estimates indicate what model specification was used. The bottom of the table shows conventional measures to evaluate goodness of fit and validity of the exclusion restriction.

${ }^{1}$ Covariates include (1) household characteristics: HH size, number of children aged $0-5$, number of adult males, dummy for mother being foreign born, age of the mother at baseline, age of the youngest child, dummies for race black, white and ethnicity Hispanic; (2) neighborhood characteristics are block-group measures of median income, population, ratio income to poverty, average years in rent, average years of schooling, proportion of people with a bachelor's degree; (3) series of eight quarterly measures of pre-baseline earnings, dummies for employment status and participation in TANF variables.

${ }^{2}$ CCR\&R agency variables: median time providers have received childcare subsidy vouchers since the program started; proportion of black, white and Hispanic cases; proportion of childcare cases related to children aged $0-3,3-5$ and 5 and older; proportion of cases relating to licensed and unlicensed childcare facilities and the total number of cases. $Z$ vector of CCR\&R-related variables excluding county fixed effects.

${ }^{3} Z$ vector of CCR\&R-related formed exclusively of county fixed effects.

${ }^{4}$ Exogeneity test is a heteroskedasticity-robust test of the null hypothesis that the probability limit of the difference between IV and OLS estimates is equal to 0 (a Hausman test). The difference distributes $\chi^{2}(q)$ with $q$ the matrix rank of the variance of the difference between the coefficients of the two estimators.

${ }^{5} \mathrm{~F}$-statistic relates to the coefficient estimate of the processing time instrumental variable.

childcare subsidy receipt. Yet in model 1 , the sign of the association between processing time and childcare subsidy receipt is positive (consistent with results we commented in Section 4.4). The values of the $\chi^{2}$ statistics from the Hausman test (and their associated $P$-values) suggest that, if we were going to employ model 1 to calculate the treatment effects of interest, we could not rule out that 
the suggested instrument is an endogenous variable. We notice that when we control for variables in vector $X$ in model 2 the instrument remains potentially endogenous. In model 2 we also observe that by including the variables in vector $X$, most of the power of the instrument is "absorbed" by those variables - notice the sharp drop in the value of the $F$-statistic between models 1 and 2 .

In Table 2 the processing time coefficient notably increased in magnitude from model 2 to model 3, where we now are conditioning the probability of participation to the CCR\&R variables in the $Z$ vector (without including county fixed effects), instead of the control variables in vector $X$ as we did in model 2 . The Hausman test results related to model 3 suggest that the treatment variable is no longer endogenous, a partial result that speaks to the importance of controlling for those factors in this research. There are not very meaningful changes in the value of the statistics that we obtain when we change from the specification in model 3 to that in model 4, which now conditions the probability of childcare subsidy receipt to both, the CCR\&R variables in the $Z$ vector (without including county fixed effects) and the control variables in vector $X$.

Model 5 in Table 2 shows that, once conditioning on the $X$ and $Z$ vectors, the marginal effect of processing time on the probability of childcare subsidy receipt is statistically significant, shows the hypothesized sign (negative) and exerts variability with substantial power (as indicated by the partial $F$-statistic measure). The specification in model 5 is also better adjusted to the DGP (as indicated by the lowest root mean squared error statistic across the models). The results obtained from model 5 suggest that, as we explained in the empirical methods section, omitting the $Z$ vector from the structural models specification would bias the estimates of the effects of processing time on the probability of subsidy receipt.

\subsection{Estimates of the effects of childcare subsidies on earnings and employment status}

Table 3 presents descriptive statistics of the employment outcome variables by subsidy recipient status and with reference to the pre- and post-baseline periods. The table summarizes the mean and standard deviations of employment rates, sum of earnings and log of earnings by subsidy receipt status and period. The values of the table can be used to compute nonparametric difference in differences estimates of the program's effects on employment status and log of earnings (indicating that the program effects are $8.2 \%$ and $43 \%$, respectively). Those estimates indicate that CCDF childcare subsidies positively affect both the extensive and intensive margins of labor supply. However, given the lack of structure implied by this estimator, those estimates are very likely biased by 
Table 3: Descriptive statistics of the outcome variables in pre- and post-baseline periods (by treatment status)

\begin{tabular}{|c|c|c|c|c|}
\hline & \multicolumn{2}{|c|}{ Subsidy recipients } & \multicolumn{2}{|r|}{ Nonrecipients } \\
\hline & One year before & One year after & One year before & One year after \\
\hline Employment rate $^{1}$ & 0.513 & 0.598 & 0.173 & 0.176 \\
\hline Standard deviation & 0.500 & 0.490 & 0.378 & 0.381 \\
\hline Mean sum of earnings ${ }^{2}$ & 4,299 & 7,790 & 4,338 & 5,747 \\
\hline Standard deviation & 4,517 & 6,457 & 5,086 & 6,289 \\
\hline Mean log of earnings ${ }^{3}$ & 7.70 & 8.45 & 7.59 & 7.91 \\
\hline Standard deviation & 1.39 & 1.26 & 1.50 & 1.49 \\
\hline
\end{tabular}

Notes: The table presents the means and the standard deviations of the employment rate, earnings and log of earning variables by treatment status statistics averaged over the year before and the year after subsidy receipt; ${ }^{1}$ The number of observations is 9,599 for subsidy recipients and 38,819 for nonrecipients; ${ }^{2}$ Among subsidy recipients, the number of observations is 4,923 the year before and 5,923 the year after; correspondingly the number of observations is 4,338 and 5,747 for nonrecipients; ${ }^{3}$ Sample sizes are the same as in note 2 .

selection into earnings, omitted observables and the inability of the difference in differences estimator to deal with time-variant unobservable characteristics. Notice that bias in this unconditional comparison is likely to arise because, as documented in Figure 1, important differences exist in pre-baseline trends in employment outcomes across mothers with distinct subsidy receipt status.

Table 4 presents the basic results of this research, adding more structure to the comparison of outcomes across the subsidy receipt status presented in Table 3. The table shows OLS (columns 1 and 4), two-stage least squares instrumental variables (2SLS-IV in columns 2 and 5) and CF estimates (columns 3 and 6) of the effects of childcare subsidies on the log of earnings and on the probability of employment. Henceforth, we call those estimates " $\delta$ estimates" to be consistent with the notation introduced in eq. [1] from Section 3.2. In Table 4, the $\delta$ estimates were computed for the first and second years after subsidy receipt (top panel) and also quarter by quarter during the first year after subsidy receipt (bottom panel). The $\delta$ coefficients were estimated including all covariates used in the participation eq. [5] from Table 2 (all variables in vectors $X$ and $Z$ ).

The OLS estimates are presented as reference values to be compared with the 2SLS-IV and CF estimates. Both the 2SLS-IV and CF estimators share $\hat{D}_{i k}$ as basic input. $\hat{D}_{i k}$ is the propensity score (or predicted value from the participation equation) expressing the probability of childcare subsidy receipt. This participation probability was estimated using a linear probability model with the 
Table 4: OLS, IV and control function $\delta$ estimates of the effects of childcare subsidies on log of earnings and employment probability

\begin{tabular}{|c|c|c|c|c|c|c|}
\hline \multirow[t]{3}{*}{ Period after receipt } & \multicolumn{3}{|c|}{ Log of earnings } & \multicolumn{3}{|c|}{ Employment probability } \\
\hline & (1) & (2) & (3) & (4) & (5) & (6) \\
\hline & OLS & 2SLS-IV & $\mathrm{CF}^{1}$ & OLS & 2SLS-IV & $\mathrm{CF}^{1}$ \\
\hline Year 1 & $\begin{array}{c}0.405 \\
(0.016)\end{array}$ & $\begin{array}{c}0.258 \\
(0.136)\end{array}$ & $\begin{array}{c}0.264 \\
(0.104)\end{array}$ & $\begin{array}{c}0.173 \\
(0.007)\end{array}$ & $\begin{array}{c}0.097 \\
(0.062)\end{array}$ & $\begin{array}{c}0.100 \\
(0.048)\end{array}$ \\
\hline Year 2 & $\begin{array}{c}0.336 \\
(0.017)\end{array}$ & $\begin{array}{c}0.196 \\
(0.143)\end{array}$ & $\begin{array}{c}0.208 \\
(0.11)\end{array}$ & $\begin{array}{c}0.144 \\
(0.007)\end{array}$ & $\begin{array}{c}0.086 \\
(0.064)\end{array}$ & $\begin{array}{l}0.092 \\
(0.05)\end{array}$ \\
\hline Quarter 1 & $\begin{array}{r}0.518 \\
(0.03)\end{array}$ & $\begin{array}{c}1.443 \\
(0.27)\end{array}$ & $\begin{array}{c}1.497 \\
(0.286)\end{array}$ & $\begin{array}{c}0.186 \\
(0.007)\end{array}$ & $\begin{array}{c}0.099 \\
(0.064)\end{array}$ & $\begin{array}{c}0.098 \\
(0.048)\end{array}$ \\
\hline Quarter 2 & $\begin{array}{c}0.377 \\
(0.034)\end{array}$ & $\begin{array}{c}0.655 \\
(0.282)\end{array}$ & $\begin{array}{c}0.232 \\
(0.312)\end{array}$ & $\begin{array}{c}0.169 \\
(0.007)\end{array}$ & $\begin{array}{c}0.085 \\
(0.066)\end{array}$ & $\begin{array}{c}0.083 \\
(0.049)\end{array}$ \\
\hline Quarter 3 & $\begin{array}{c}0.319 \\
(0.033)\end{array}$ & $\begin{array}{c}0.519 \\
(0.124)\end{array}$ & $\begin{array}{c}0.929 \\
(0.313)\end{array}$ & $\begin{array}{c}0.148 \\
(0.008)\end{array}$ & $\begin{array}{c}0.146 \\
(0.067)\end{array}$ & $\begin{array}{r}0.147 \\
(0.05)\end{array}$ \\
\hline Quarter 4 & $\begin{array}{c}0.299 \\
(0.035)\end{array}$ & $\begin{array}{c}0.187 \\
(0.176)\end{array}$ & $\begin{array}{c}0.070 \\
(0.331)\end{array}$ & $\begin{array}{c}0.149 \\
(0.008)\end{array}$ & $\begin{array}{c}0.161 \\
(0.068)\end{array}$ & $\begin{array}{c}0.164 \\
(0.05)\end{array}$ \\
\hline
\end{tabular}

Notes: The table presents coefficient estimates (standard errors below) of the effects of childcare subsidies on log of earnings (left panel) and employment probability (right panel) using OLS, IV-2SLS and CF estimators. The regressions were done separately for every row, i.e. every year/quarter in this table. The left-hand column indicates the period after subsidy receipt for which estimates were calculated. All outcome equations included the following covariates: (1) household characteristics: $\mathrm{HH}$ size, number of children aged 0-5, number of adult males, dummy for mother being foreign born, age of the mother at baseline, age of the youngest child, dummies for race black, white and ethnicity Hispanic; (2) neighborhood characteristics as block-group measures of: median income, population, ratio income to poverty, average years in rent, average years of schooling, proportion of people with a bachelor's degree and (3) series of eight quarterly measures of pre-baseline earnings, dummies for employment status and participation in TANF variables. The first stage equation employed to estimate the values in columns 2 and 5 was taken from eq. [5] in Table 2.

${ }^{1} \mathrm{CF}$ stands for control function estimator. The outcome equations in the CF estimates included a fourth exponential series of the propensity score estimated in model specification 5 of Table 2 as a selection correction factor.

specification indicated in column 5 from Table 2. The CF estimators included a fourth exponential series in that propensity score as a semi-parametric selection correction factor. ${ }^{4}$

4 Since, as demonstrated, the propensity score is generated from the model of best fit, we maximize the likelihood that the estimated treatment effect parameters are calculated on areas where the probability of subsidy receipt is close to 0 and 1 (a required condition for control function estimators). 
The results in the top left panel of Table 4 evident similar 2SLS-IV and CF estimates of $\delta$ associated with the log of earnings: the childcare subsidy program appears to have a positive $\delta$ effect on earnings (around 25\%) during the first year after subsidy receipt. The effect appears to fade out during the second year after mothers begin receiving program benefits. The bottom left panel of Table 4 reveals the dynamic nature of showing $\delta$ estimates quarter by quarter for the first four-quarters after subsidy receipt. A substantial impact of the program during the first quarter is followed by effects that quickly fade out with time. The left panel of Table 4 reveals that the effects of childcare subsidies on the earnings of low-income mothers are positive and statistically significant during the first year after subsidy receipt, and those average effects on earnings are heavily concentrated in the first three-quarters of that first year.

The impact of childcare subsidies receipt on employment status is studied in the right panel of Table 4. Results suggest that the childcare subsidy program exerts positive impacts upon the employment status of participant mothers. The employment rate of recipients is 10 percentage points higher than the same rate among nonrecipients. Different from the effects on earnings, the bottom right panel in Table 4 shows that the positive $\delta$ effects of childcare subsidies on employment status appear sustained dynamically throughout the first year after subsidy receipt.

What do we learn about the parameters estimated from the differences that can be observed across the OLS, IV and CF estimators in Table 4? Firstly, notice that in comparing estimates from these three estimators, the direction of the effects is the same. Childcare subsidies appear to have invariably positive effects on the outcomes of interest irrespective of the estimator utilized. Also notice that the magnitudes of the point estimates, despite different, cannot straightforwardly claimed to be statistically distinct given the confidence intervals associated with the standard errors presented in Table $4 .^{5}$ Notice, however, that the parameter estimates from IV and CF tend to be more similar among them than when compared to OLS. Combined, those results suggest that, estimates from OLS are more likely to be biased than those from IV and CF, a result that we primarily adjudicate to unaddressed reverse causality problems in OLS, as we mentioned in Section 3.1. Also, in light of our discussion in Section 3.1, the results in Table 4 suggest that both IV and CF are estimating the same parameter, and that this parameter is a "TT" one expressing the effects of the childcare subsidy program on the earnings and employment status of participant mothers.

5 There is a big difference in the magnitude of the standard errors when OLS is compared to IV and CF estimators. The reason for that is that OLS exploits the full sample variability directly in one single step, while both IV and CF induce variability in the outcomes utilizing the predicted variability from a first-stage model, which greatly reduces statistical power. 
Combined, the results associated with earnings and employment status reveal a situation in which a substantial portion of the effects on earnings is driven by employment effects: the overall effects of the childcare subsidy program come into play on the extensive margin of labor supply. The results presented here are consistent with those observed in graphs A and B in Figure 1, which suggested the pattern of change in the earnings series was motivated by variations in the extensive margin of labor supply. During the pre-baseline period, a sharp increase in earnings occurs among subsidy recipients that was paralleled (and we hypothesized caused) by a similar discontinuity in the employment rate. Childcare subsidy programs lower the reservation wage among unemployed mothers (and/or those out of the labor force) inducing them to work: the effects of the program on earnings are driven by movements from no earnings to some earnings as many mothers start new employment periods.

\subsection{Estimates of effects on relevant subpopulations}

By estimating the effects of CCDF childcare subsidies on earnings for selected subgroups, we reveal the heterogeneity of this program's effects among populations that are of substantive interest for policymakers. In this section we present and briefly discuss estimates of the $\delta$ treatment effect across neighborhood poverty, age of the mothers and employment status the year before the baseline quarter. In Table 5 we present estimates of the program effects using OLS, 2SLSIV and CF estimates of the $\delta$ effects across the subgroups formed by mothers in: (A) high-poverty neighborhoods $(N=5,521)$; (B) not high-poverty neighborhoods $(N=12,897)$; (C) ages 18-24 $(N=21,165)$; (D) ages $25+(N=27,250)$; (E) employed in the pre-baseline period $(N=11,626)$; (F) not employed in the pre-baseline period $(N=36,792)$. High-poverty neighborhoods were defined as neighborhoods where at least $40 \%$ of the households had incomes at or below $100 \%$ of the federal poverty line (FPL). Mothers were considered employed in the pre-baseline period if they exhibit UI earnings at least one-quarter during the year preceding that time.

Evaluating the effects of the childcare subsidy program by neighborhood poverty, we observe that the $\delta$ effects on employment and earnings of mothers living in high-poverty neighborhoods are nonsignificant at conventional levels as to reject a zero effect (which might be driven by a small sample size). However, there are positive and statistically significant effects on earnings (but not on employment probability) of mothers who participate in childcare subsidies and do not live in high-poverty neighborhoods. Notice that the effects on earnings for the latter group of mothers are present only during the first year after subsidy receipt. 
Table 5: OLS, IV and CF $\delta$ estimates of the effects of childcare subsidies (by concentration of poverty in neighborhood, maternal age range and employment status in the pre-baseline period)

\begin{tabular}{|c|c|c|c|c|c|c|}
\hline & \multicolumn{3}{|c|}{ Log of earnings } & \multicolumn{3}{|c|}{ Employment probability } \\
\hline & OLS & 2SLS-IV & $\mathrm{CF}^{1}$ & OLS & 2SLS-IV & $\mathrm{CF}^{1}$ \\
\hline \multicolumn{7}{|c|}{ A) In high-poverty neighborhoods ${ }^{2}$} \\
\hline Year 1 & $\begin{array}{r}0.092 \\
(0.011)\end{array}$ & $\begin{array}{c}0.146 \\
(0.163)\end{array}$ & $\begin{array}{c}0.124 \\
(0.125)\end{array}$ & $\begin{array}{r}0.219 \\
(0.02)\end{array}$ & $\begin{array}{c}0.365 \\
(0.213)\end{array}$ & $\begin{array}{c}0.359 \\
(0.185)\end{array}$ \\
\hline Year 2 & $\begin{array}{c}0.075 \\
(0.017)\end{array}$ & $\begin{array}{r}-0.038 \\
(0.131)\end{array}$ & $\begin{array}{r}-0.063 \\
(0.175)\end{array}$ & $\begin{array}{c}0.188 \\
(0.02)\end{array}$ & $\begin{array}{c}0.312 \\
(0.215)\end{array}$ & $\begin{array}{c}0.31 \\
(0.189)\end{array}$ \\
\hline \multicolumn{7}{|c|}{ B) Not in high-poverty neighborhoods } \\
\hline Year 1 & $\begin{array}{c}0.076 \\
(0.004)\end{array}$ & $\begin{array}{c}0.112 \\
(0.035)\end{array}$ & $\begin{array}{c}0.112 \\
(0.043)\end{array}$ & $\begin{array}{c}0.164 \\
(0.008)\end{array}$ & $\begin{array}{c}0.068 \\
(0.066)\end{array}$ & $\begin{array}{c}0.075 \\
(0.05)\end{array}$ \\
\hline Year 2 & $\begin{array}{c}0.059 \\
(0.005)\end{array}$ & $\begin{array}{c}0.041 \\
(0.045)\end{array}$ & $\begin{array}{c}0.043 \\
(0.05)\end{array}$ & $\begin{array}{c}0.136 \\
(0.008)\end{array}$ & $\begin{array}{c}0.06 \\
(0.068)\end{array}$ & $\begin{array}{c}0.07 \\
(0.052)\end{array}$ \\
\hline \multicolumn{7}{|c|}{ C) Mothers aged $18-24$} \\
\hline Year 1 & $\begin{array}{c}0.348 \\
(0.022)\end{array}$ & $\begin{array}{c}0.307 \\
(0.177)\end{array}$ & $\begin{array}{c}0.322 \\
(0.075)\end{array}$ & $\begin{array}{c}0.146 \\
(0.01)\end{array}$ & $\begin{array}{r}0.121 \\
(0.08)\end{array}$ & $\begin{array}{c}0.129 \\
(0.071)\end{array}$ \\
\hline Year 2 & $\begin{array}{c}0.292 \\
(0.024)\end{array}$ & $\begin{array}{c}0.196 \\
(0.183)\end{array}$ & $\begin{array}{c}0.219 \\
(0.074)\end{array}$ & $\begin{array}{c}0.124 \\
(0.011)\end{array}$ & $\begin{array}{c}0.084 \\
(0.082)\end{array}$ & $\begin{array}{c}0.095 \\
(0.074)\end{array}$ \\
\hline \multicolumn{7}{|c|}{ D) Mothers aged $25+$} \\
\hline Year 1 & $\begin{array}{c}0.454 \\
(0.022)\end{array}$ & $\begin{array}{r}0.268 \\
(0.211)\end{array}$ & $\begin{array}{c}0.248 \\
(0.069)\end{array}$ & $\begin{array}{l}0.196 \\
(0.01)\end{array}$ & $\begin{array}{c}0.099 \\
(0.095)\end{array}$ & $\begin{array}{c}0.089 \\
(0.067)\end{array}$ \\
\hline Year 2 & $\begin{array}{c}0.374 \\
(0.023)\end{array}$ & $\begin{array}{c}0.198 \\
(0.222)\end{array}$ & $\begin{array}{c}0.177 \\
(0.069)\end{array}$ & $\begin{array}{c}0.162 \\
(0.01)\end{array}$ & $\begin{array}{c}0.087 \\
(0.099)\end{array}$ & $\begin{array}{c}0.077 \\
(0.069)\end{array}$ \\
\hline \multicolumn{7}{|c|}{ E) Employed pre-baseline ${ }^{3}$} \\
\hline Year 1 & $\begin{array}{c}0.307 \\
(0.018)\end{array}$ & $\begin{array}{c}0.27 \\
(0.157)\end{array}$ & $\begin{array}{c}0.267 \\
(0.192)\end{array}$ & $\begin{array}{c}0.114 \\
(0.008)\end{array}$ & $\begin{array}{c}0.078 \\
(0.069)\end{array}$ & $\begin{array}{c}0.078 \\
(0.087)\end{array}$ \\
\hline Year 2 & $\begin{array}{c}0.259 \\
(0.024)\end{array}$ & $\begin{array}{c}0.018 \\
(0.215)\end{array}$ & $\begin{array}{c}0.006 \\
(0.234)\end{array}$ & $\begin{array}{r}0.099 \\
(0.011)\end{array}$ & $\begin{array}{c}-0.002 \\
(0.094)\end{array}$ & $\begin{array}{r}-0.008 \\
(0.105)\end{array}$ \\
\hline \multicolumn{7}{|c|}{ F) Not employed pre-baseline } \\
\hline Year 1 & $\begin{array}{c}0.365 \\
(0.022)\end{array}$ & $\begin{array}{c}0.29 \\
(0.189)\end{array}$ & $\begin{array}{r}0.267 \\
(0.115)\end{array}$ & $\begin{array}{c}0.164 \\
(0.01)\end{array}$ & $\begin{array}{l}0.13 \\
(0.086)\end{array}$ & $\begin{array}{c}0.119 \\
(0.054)\end{array}$ \\
\hline Year 2 & $\begin{array}{c}0.297 \\
(0.021)\end{array}$ & $\begin{array}{c}0.281 \\
(0.165)\end{array}$ & $\begin{array}{c}0.28 \\
(0.111)\end{array}$ & $\begin{array}{c}0.133 \\
(0.01)\end{array}$ & $\begin{array}{c}0.129 \\
(0.075)\end{array}$ & $\begin{array}{c}0.129 \\
(0.051)\end{array}$ \\
\hline
\end{tabular}

Notes: The table presents coefficient estimates (standard errors below) of the effects of childcare subsidies on log of earnings (left panel) and employment probability (right panel) using OLS, IV-2SLS and CF estimators for selected subpopulations. The regressions were done separately for every row, i.e. every year/quarter in this table. The sample sizes for the subpopulations are: (A) high-poverty neighborhoods $N=5,521$; (B) nonhigh-poverty neighborhoods $N=42,897$; (C) mothers aged 18-24 $N=21,165$; (D) mothers aged $25+N=27,256$; (E) employed in the pre-baseline period $\times 11.020$; $(F)$ not employed in the pre-baseline period $N=36,792 ;{ }^{1}$ The outcome equations in the CF estimates included a fourth exponential series of the propensity score estimated in model 5 of Table 2 as a selection correction factor; ${ }^{2} \mathrm{High}$ poverty neighborhoods are where $40 \%$ or more households have incomes $0-100 \%$ of the FPL; ${ }^{3}$ Employed in the pre-baseline period if mother exhibits earnings for at least one-quarter in any of the four preceding quarters. 
The effects of the childcare subsidies program on earnings appear relatively invariant to the age at which mothers enrolled in the program. Comparing the effects of the program on mothers in the 18-24 age group with those in the $25+$ age group from Table 5, we observe that $\delta$ effects on the group of younger mothers do not differ from those effects on older mothers. The $\delta$ effects across the subsamples defined by the age of the mother also appear consistent with the overall picture found in Table 4, according to which, the employment status effects drive the earnings effects.

Table 5 also analyzes the $\delta$ effects for the subpopulations of mothers defined by their employment status in the pre-baseline period. We notice that irrespective of their employment status before subsidy receipt, mothers experienced a positive effect on earnings during the first year after program participation. Interestingly, those effects on earnings fade during the second year after subsidy receipt only among mothers who were employed in the pre-baseline period. As expected, mothers employed in the pre-baseline period do not see their employment status change as the result of subsidy receipt, but mothers who were not employed in the pre-baseline period do experience a change in their employment likelihood.

\section{Conclusions}

Current literature examining how childcare subsidies affect low-income families has a gap: little direct empirical evidence exists regarding how the earnings and employment status of low-income families are affected by the most important childcare subsidy program in the US - the CCDF program. Estimates of the effects of CCDF-funded childcare programs on earnings and employment probability are of fundamental value in any comprehensive cost-benefit analysis of this policy. Our study contributes to filling this knowledge gap by generating point value estimates of those effects and characterizing their dynamically heterogenous nature.

Grounded in rigorous analysis of data, our research also provides insights into the nature of the selection process that drives low-income mothers to participate in CCDF childcare subsidy programs (complementing the work of studies, notably Meyers, Heintze, and Wolf (2002) and Herbst (2008)). We have highlighted that the dynamic of pre-baseline earnings, employment and TANF participation predicts the probability of subsidy receipt. To the best of our knowledge, our study is the first to document the importance of those prebaseline dynamics as fundamental predictors of enrollment in the CCDF program. 
The present research suggests that in the short term, childcare subsidies are effective at promoting employment outcomes for low-income mothers. On average, mothers receiving childcare subsidies exhibit higher earnings and employment probabilities than they would have exhibited absent their participation in the program. Those effects are primarily driven by changes in the extensive margin of labor supply. Despite being positive, the short-term effects are modest, and they fade with time (presumably while mothers remain enrolled in the program). Our results also indicate that various subpopulations are affected differently by the childcare subsidies program, a finding with relevant implications for policy design. Less-poor and unemployed mothers comprise the subgroups that appear to benefit the most from participation. Highlighting this heterogeneity of effects across recipients of CCDF benefits allows policy makers to improve the policy's overall effects by targeting those subpopulations where the expected return is the highest.

The present research has some limitations. Given that the population analyzed was drawn from a pool of Food Stamp recipients in year 2000, our findings speak to program effects on very low income mothers in that year (in year 2000, the year we sampled those households, the income eligibility threshold for Food Stamps receipt was $130 \%$ of the FPL). Despite there are good reasons to assess the effects of the CCDF program on those very low-income mothers, whether we can generalize our findings to the full population of households that were eligible for CCDF is uncertain, given that those households were, on average, less poor than those in our sample (the income eligibility threshold for CCDF was $200 \%$ of the FPL in year 2000). Also, the CCDF has unique features in each state of the United States and those features have been subject to change since year 2000 (as we indicated, the states have a lot of leverage to set their own eligibility rules beyond the federal standards we described in Section 2.2). Our results are, therefore, suggestive of how the CCDF program currently affects the employment outcomes of low-income mothers in the United States.

CCDF-funded childcare subsidy programs impact two generations: mothers and their children. In this paper, we have shown that those subsidies modestly affect the employment outcomes of participant mothers. The CCDF program, however, also has the potential to affect the developmental trajectories of the children whose mothers use it (see, for instance, Herbst and Tekin (2010)). While the CCDF program impacts earnings and employment status, a comprehensive cost-benefit analysis should assess whether or not the program also affects the developmental prospects of the children of participant mothers. Research on this issue is in its early stages. Further research on this topic should be encouraged to provide a comprehensive assessment of the social benefits of the investment represented by this program. 
Acknowledgment: The authors wish to thank Dan Black, Robert Lalonde and Robert Goerge for their valuable comments on previous drafts of this paper. Thanks to the Ford Foundation for generous funding provided to Chapin Hall to conduct this research.

\section{Appendix A: Administrative databases}

The following databases are hosted at Chapin Hall at the University of Chicago, where raw tables with records from public agencies are routinely translated into relational databases, and linked using probabilistic record linkage (Goerge, Voorhis, and Lee 1994). Previous research on the economics of children and families that use those relational databases includes Zanoni, Doyle (2007).

Illinois Longitudinal Public Assistance Research Database (ILPARD): ILPARD is a relational database that comprises more than 20 million records of program eligibility and participation in the SNAP, TANF and Medicaid programs in Illinois from 1989 until the present. Chapin Hall at the University of Chicago uses matching record linkage methods to update data extracts provided by the Illinois Department of Human Services on a monthly basis. Providing data at the individual, household and case record levels, ILPARD is extensively rich, detailing participation in these programs as well as identifying basic demographic characteristics at baseline. The database also contains longitudinal records of household addresses and their changes which have been geocoded.

Child Care Tracking System (CCTS): CCTS is a relational database of administrative records that tracks CCAP payments made by the Illinois Department of Human Services between 1997 and 2011. CCTS data identify the childcare provider and other characteristics of the subsidy program such as the amount paid for childcare and whether the care provided is part-time or full-time. The data also provide household-level information, demographics and addresses of families and providers.

Unemployment Insurance Wage Reporting Database (UIWRD): This database is built from extracts taken from the Illinois Department of Employment Security's (IDES) Online Data Entry and Display System (ODEDS). The data contains quarterly wage records as they are reported to the IDES for most wage earners in Illinois. Businesses that employ one or more individuals within any 20-week period in a calendar year are required to report employee wages for unemployment insurance purposes (certain types of nonprofits and local government entities are exempted from this rule). The state estimates that approximately $95 \%$ of all paid jobs in Illinois are contained in this database. 


\section{Appendix B: CCR\&R's regional geographic areas served (Illinois-Year 2000)}

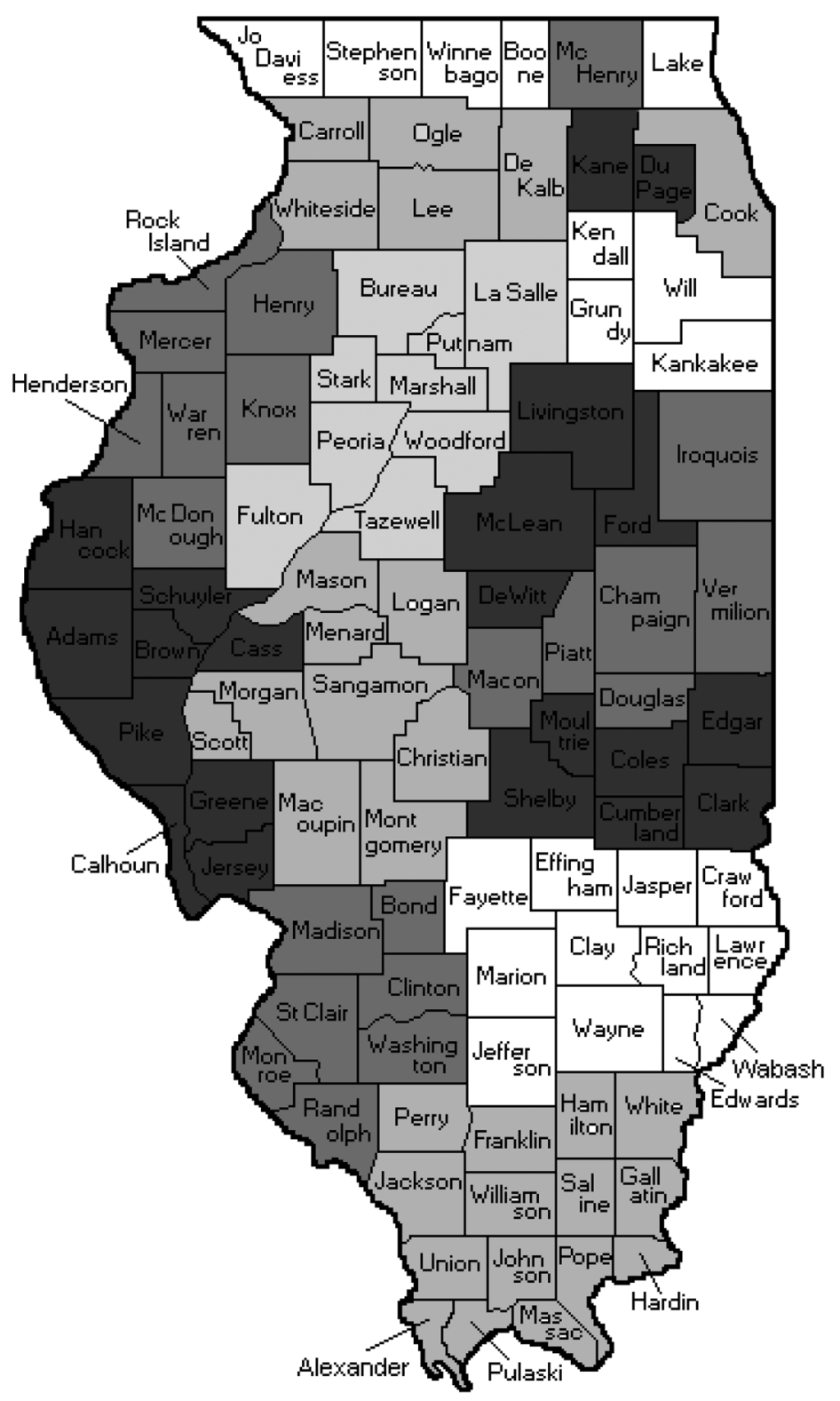




\section{Appendix C: Instrumental variable}

Table 6: Descriptive statistics of the IV (processing time)

\begin{tabular}{|c|c|c|c|c|c|c|c|c|c|}
\hline & \multicolumn{5}{|c|}{ Whole sample } & \multicolumn{4}{|c|}{ Mean value by baseline quarter in 2000} \\
\hline & Mean & SE & Min & Max & Obs. & 1st qrt. & 2nd qrt. & 3rd qrt. & 4th qrt. \\
\hline Subsidy recipients & 40.81 & 0.008 & 37 & 42 & 38,819 & 40.81 & 40.81 & 40.81 & 40.81 \\
\hline Comparison group & 41.09 & 0.012 & 37 & 52.5 & 9,599 & 41.09 & 41.10 & 40.76 & 41.62 \\
\hline
\end{tabular}

Notes: the values in the table show the unconditional mean of the CCR\&R processing time variable for the whole sample (left panel) and by baseline quarter in 2000 .

Table 7: Associations between the treatment variable and the instrumental variable

\begin{tabular}{lrr}
\hline & Unconditional & Conditioning on Z and county F.E. \\
\hline Correlation coefficient & 0.0775 & -0.0643 \\
Significance level & $(0.0000)$ & $(0.0000)$ \\
$\beta$ OLS coefficient & 0.0216 & -0.1162 \\
SE $(\beta)$ & $(0.0012)$ & $(0.0050)$ \\
\hline
\end{tabular}

Notes: The values in the table are measures of the statistical associations between the treatment and the instrumental variables; unconditional (top row) and conditional on variables in vector $Z$ and county fixed effects (bottom, row).

Table 8: Probability of changing CCR\&R region before the baseline period

\begin{tabular}{lrrrr}
\hline & \multicolumn{3}{c}{ Baseline period in year 2000 } \\
\cline { 2 - 5 } & 1st qrt. & 2nd qrt. & 3rd qrt. & 4th qrt. \\
\hline One-quarter before & 0.001 & 0.0052 & 0.0068 & 0.0051 \\
Two-quarters before & 0.0079 & 0.0125 & 0.0105 & 0.0023 \\
\hline
\end{tabular}

Notes: The values in the table show the probability that a household will act strategically by moving to a different CCR\&R region either one- or two-quarters before the baseline period. Sample size is 48,418 households.

\section{References}

Berger, M. C., and D. A. Black. 1992. "Child Care Subsidies, Qualities of Care, and the Labor Supply of Low-Income, Single Mothers." The Review of Economics and Statistics 740(4):635-42. 
Black, D. A., and J. A. Smith. 2006. "Estimating the Returns to College Quality with Multiple Proxies for Quality." Journal of Labor Economics 240:3.

Blau, D., and J. Currie. 2004. "Preschool, Day Care, and After School Care: Who's Minding the Kids?” Working Paper 10670, NBER.

Blau, D., and P. K. Robins. 1998. "Child-Care Costs and Family Labor Supply." The Review of Economic and Statistics 700(3):374-81.

Blau, D., and E. Tekin. 2007. "The Determinants and Consequences of Child Care Subsidies for Single Mothers in the USA." Journal of Population Economics 200(4):719-41.

Cascio, E. U. 2009. "Maternal Labor Supply and the Introduction of Kindergartens into American Public Schools." Journal of Human Resources 440(1):140-70.

Connelly, R. 1992. "The Effect of Child Care Costs on Married Women's Labor Force Participation." The Review of Economics and Statistics 740(1):83-90.

Doyle, J. J. 2007. "Child Protection and Child Outcomes: Measuring the Effects of Foster Care." American Economic Review 97(5):1583-1610.

Fitzpatrick, M. D. 2010. "Preschoolers Enrolled and Mothers at Work? The Effects of Universal Prekindergarten." Journal of Labor Economics 280(1):51-85.

Gelbach, J. 2002. "Public Schooling for Young Children and Maternal Labor Supply." American Economic Review 92:307-22.

Goerge, R., J. Voorhis, and B. J. Lee 1994. "Illinois's Longitudinal and Relational Child and Family Research Database.” Social Science Computer Review 1994, 12:351-365.

Heckman, J. 1974. "Effects of Child-Care Programs on Women S Work Effort." Journal of Political Economy 820(2):136-63.

Heckman, J. 2007. "The Technology of Skill Formation the Technology." The American Economic Review 970(2):31-47.

Heckman, J., and S. Navarro-Lozano. 2004. "Using Matching, Instrumental Variables, and Control Functions to Estimate Economic Choice Models." The Review of Economics and Statistics 860(1):30-57.

Heckman, J. J., S. Urzua, and E. Vytlacil. 2006. "Understanding Instrumental Variables in Models with Essential Heterogeneity." Review of Economics and Statistics 880(3): 389-432.

Herbst, C. M. 2008. "Who Are the Eligible Non-Recipients of Child Care Subsidies?" Children and Youth Services Review 300(9):1037-54. ISSN 01907409

Herbst, C. M., and E. Tekin. 2010. "The Impact of Child Care Subsidies on Child Well-Being: Evidence from Geographic Variation in the Distance to Social Service Agencies." Working Paper 16250, NBER.

Kimmel, J. 1995. "The Effectiveness of Child-Care Subsidies in Encouraging the Welfare-to-Work Transition of Low-Income Single Mothers." The American Economic Review 850(2):271-5.

Meyers, M. K., T. Heintze, and D. A. Wolf. 2002. "Child Care Subsidies and the Employment of Welfare Recipients.” Demography 390(1):165-79. ISSN 0070-3370

Michalopoulos, C., E. Lundquist, and N. Castells. 2010. "The Effects of Child Care Subsidies for Families in Cook County, Illinois.” Technical Report September 2010, Office of Planning, Research and Evaluation, Administration for Children and Families, Washington, DC.

Michalopoulos, C., P. K. Robins, and I. Garfinkel. 1992. "A Structural Model of Labor Supply and Child Care Demand." Journal of Human Resources 270(1):166-203.

Ribar, D. 1995. "Model of Child Care and the Labor Supply of Married Women." Journal of Labor Economics 130(3):558-97. 
Tekin, E.2005. "Child Care Subsidy Receipt, Employment, and Child Care Choices of Single Mothers." Economics Letters 890(1).

Tekin, E. 2007. "Childcare Subsidies, Wages, and Employment of Single Mothers." Journal of Human Resources 420(2):453-87.

Witte, A. D., M. Queralt, and H. Griesinger. 2000. “Changing Policies, Changing Impacts: Employment and Earnings of Child Care Subsidy Recipients in the Era of Welfare Reform." Social Service Review 740(4):588-619. 